\title{
A school microepidemic of tuberculosis
}

\author{
C P Bredin, M Godfrey, J McKiernan
}

\begin{abstract}
Background Microepidemics of tuberculosis continue to occur in countries with a low incidence of tuberculosis. Methods and results A microepidemic of tuberculosis in a secondary school with 604 girls in Cork city, Ireland, in 1986 with follow up to 1990 is described. Neonatal BCG vaccination was discontinued in the city in December 1972 so most of the 342 pupils who had received BCG were aged 14 years or more. Six active cases and 75 tuberculin positive cases were found. Four of the six girls with active disease had had neonatal BCG. The 75 pupils with a positive (grade 3 or 4) Heaf test response were given chemoprophylaxis with rifampicin and isoniazid for six months; none had developed active tuberculosis four years later. The brother of the girl who was the probable index case, however, developed active tuberculosis in 1988 despite similar chemoprophylaxis.

Conclusion The episode highlights the fact that children who have had neonatal BCG can develop active tuberculosis as teenagers.
\end{abstract}

Department of Respiratory Medicine C P Bredin Child Health Clinic M Godfrey

Department of

Paediatrics J McKiernan

St Finbarr's and Regional Hospitals, Cork, Ireland

Reprint requests to: Dr Bredin

Accepted 19 September 1991
Although the incidence of tuberculosis continues to fall in the Republic of Ireland, ${ }^{1-3}$ group infections or microepidemics continue to occur, ${ }^{4}$ as in the United Kingdom ${ }^{5}$ and other European countries. ${ }^{6}$ Such an episode occurred in 1986 in a girls' secondary school in Cork city, where the policy of neonatal BCG vaccination had been discontinued in December 1972. The area has a low tuberculin positivity rate ${ }^{2}(1.4$ per cent Heaf grade 2 or greater in non-BCG 12 year olds), although higher than the national average $(0.9$ per cent). ${ }^{7}$ All the girls were white.
Table 1 Tuberculosis in the school: deiails of active cases

\begin{tabular}{lllll}
\hline Case & $\begin{array}{l}\text { Age } \\
(y)\end{array}$ & $\begin{array}{l}\text { Month of } \\
\text { presentation } \\
(1986)\end{array}$ & Type of tuberculosis & $\begin{array}{l}\text { Neonatal } \\
B C G\end{array}$ \\
\hline A & 13 & Feb & $\begin{array}{l}\text { Tuberculous meningitis } \\
\text { Miliary tuberculosis }\end{array}$ & No \\
$\mathrm{B}^{\star}$ & 14 & May & $\begin{array}{l}\text { Endometrial } \\
\text { Smear positive }\end{array}$ & Yes \\
$\mathrm{C}^{\star}$ & 14 & Aug & $\begin{array}{l}\text { Pulmonary tuberculosis } \\
\text { Smear positive }\end{array}$ & Yes \\
$\mathrm{D}^{\star}$ & 14 & Sept & $\begin{array}{l}\text { Pulmonary tuberculosis } \\
\text { Pleural tuberculosis }\end{array}$ & Yes \\
$\mathrm{E}^{\star}$ & 14 & Oct & Primary pulmonary tuberculosis & Yes \\
F & 13 & Oct & No \\
\hline
\end{tabular}

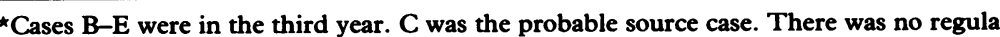
social contact between the two smear positive cases (C and D) and the two second year cases (A and F). All cases were tuberculin positive.

\section{Cases and contact tracing}

A 13 year old girl (case A) developed tuberculous meningitis in February 1986 (table 1). Contact tracing of close contacts, including her family, yielded no further cases of tuberculous infection. Two months later a 14 year old pupil at the same school (case B) presented with excessive vaginal bleeding and a diagnosis of endometrial tuberculosis was made (positive histological specimen and culture). Contact tracing of close contacts again identified no further cases. Four months later smear positive pulmonary tuberculosis was diagnosed in another pupil (case C). Her chest radiograph showed extensive consolidation. Tuberculin tests gave positive responses in her three brothers. Contact tracing was then extended to all pupils and staff at the school.

The student body consisted of five years (1st to 5 th) of approximately equal size, age range 12-18 years. A tuberculin test (Heaf) was carried out on all pupils and siblings of individuals with active disease. To allow for the effect of neonatal BCG vaccination and non-tuberculous mycobacterial infection, only Heaf test grades 3 and 4 were interpreted as positive responses; ${ }^{8}$ if the Heaf test response was positive a chest radiograph was obtained; if it was negative the test was repeated after six weeks. Adult family contacts and school staff, in accordance with local policy, had chest radiography only. Those with active disease were treated with rifampicin 450 or $600 \mathrm{mg}$ and isoniazid $300 \mathrm{mg}$ daily for nine months, with ethambutol $15 \mathrm{mg} / \mathrm{kg}$ for the first two months. Pupils with a positive response to the Heaf test and a normal chest radiograph were given rifampicin and isoniazid as chemoprophylaxis for six months. Neonatal BCG vaccination was confirmed by the presence of a scar or signed community care records, or both. Where there was no scar and no record the pupil was included in the non-BCG group.

\section{Results}

The results of contact tracing of the 604 pupils are outlined in table 2 . Seventy eight pupils had a positive Heaf test response, three of whom had an abnormal chest radiograph. These three pupils were treated for active tuberculosis (table 1 , cases D, E, and F); the other 75 pupils received prophylaxis. Patient $D$ had smear positive pulmonary tuberculosis and a single $2 \mathrm{~cm}$ cavity in the right upper lobe on the chest radiograph. Contact tracing of her family and of several families in the neighbourhood for whom she acted as a babysitter had negative results. As the contact 
Table 2 Contact tracing in school pupils: tuberculin (Heaf) test and radiographic results

\begin{tabular}{lc}
\hline INITIAL TESTS $(\mathrm{n}=604)$ & \\
Heaf response & \\
Negative & 530 \\
Positive & 74 \\
Chest radiograph & \\
$\quad$ Normal & 71 \\
Abnormal & $3 \dagger$ \\
REPEAT TUBERCULIN TEST IN 6-8 WEEKS $(\mathrm{n}=530)$ & \\
Heaf response & \\
$\quad$ Negative & 526 \\
Positive & 4 \\
Chest radiograph:^ normal & 4 \\
\hline
\end{tabular}

${ }^{\star}$ Chest radiographs obtained from children with Heaf grades 3-4.

†Cases D, E, and F (table 1).

tracing results of the family of the other girl with smear positive pulmonary tuberculosis (case $\mathrm{C}$ ) were positive we concluded that she was the probable index case.

In the bacteriologically confirmed cases (AD) Mycobacterium tuberculosis was sensitive to isoniazid, rifampicin, ethambutol, and streptomycin. None of the six girls with active disease relapsed after treatment, and none of the 75 pupils given chemoprophylaxis had developed active tuberculosis by 1990 . The 9 year old brother of the girl who was the probable index case (case C) developed pulmonary, pleural, and cervical gland tuberculosis in October 1988. At contact tracing in 1986 he had a grade 3 positive Heaf test response and a normal chest radiograph and had received six months' chemoprophylaxis.

In the third year classes $36 \%$ were tuberculin positive. This was the year of the probable index case and the two smear positive cases. In this year 68 had had neonatal BCG and 49 had not. Four of the six active cases had had neonatal BCG but not case A, the girl who developed tuberculous meningitis. Of the 342 children who had received neonatal BCG, $63 \%$ had a grade 1 or 2 Heaf result, compared with $85 \%$ of the 262 children who had not had neonatal BCG. No active cases of tuberculosis were found among the school staff.

\section{Discussion}

This report shows that microepidemics of tuberculosis may occur in areas of low prevalence of the disease and in teenagers who had received neonatal BCG. The protective effect of neonatal BCG in teenagers cannot be determined because the number of active tuberculosis cases in the BCG $(n=4)$ and non-BCG pupils $(n=2)$ is too small for statis- tical comparison and because the proportion of children who had had neonatal BCG varied in the different years and hence confounds the effect of contact with the index case. There are no good grounds to revert to the pre-1972 policy of routine neonatal BCG, though the occurrence of tuberculous meningitis (case $A$ ) in a non-BCG pupil is a cause for concern.

Since this paper was submitted a similar secondary school episode in 1986 , in north west Ireland (Donegal), has been reported. ${ }^{9}$ This suggests a protective role for neonatal BCG in teenagers. This apparent lesson from Donegal may not be applicable to at least some other areas in Ireland, including Cork city, because of two possibly interrelated factors. Firstly, the Donegal episode was due to isoniazid resistant Mycobacterium tuberculosis and, secondly, many of the Donegal teenagers were children of returned emigrants or were born outside the school community care area. In Cork, however, isoniazid resistance is very rare, and the teenagers we have described were born mainly in the school locality.

The development of active tuberculosis in 1988 in a brother of the probable index case, despite six months' chemoprophylaxis with izoniazid $300 \mathrm{mg}$ and rifampicin $450 \mathrm{mg}$ daily, raises the question of the value of chemoprophylaxis. There was no evidence of noncompliance with his regimen and no evidence of drug resistance. No active disease had developed in the 75 school contacts given chemoprophylaxis by 1990, supporting the value of chemoprophylaxis in preventing active tuberculosis despite its failure in one patient.

1 Department of Health. Health statistics. Dublin: Stationery Office, 1989:30-1.

2 Policy on BCG vaccination-a review. Eastern Health Board, Dublin, 1988:43, 93

3 O'Malley G, Bredin CP. Bacteriological status of notified tuberculosis cases in the Republic of Ireland 1983-6. Ir Med Sci 1988;157:307-9.

4 Connolly K, Murphy C. A school outbreak of tuberculosis. Ir Med J 1987;80:415.

5 Frew AJ, Mayon-White RT, Benson RK. An outbreak of tuberculosis in an Oxfordshire school. Br J Dis Chest 1987;81:293-5.

6 Trnka L. Features of tuberculosis micro-epidemics in Europe. In: Proceedings of the joint SEP/SEPCR meeting 1986. Book of abstracts, vol 2. Paris: SEP/SEPCR, 1986.

7 Horgan JM, Daly L, O'Boyle M. Results of a study of tuberculin conversion rates in primary school children in Ireland. Ir J Med Sci 1988;157:252-5.

8 Snider DE. BCG vaccinations and tuberculin skin tests. JAMA 1985;253:3438-9.

9 Shannon A, Kelly P, Lucey M, Cooney M, Corcoran P Clancy $L$, et al. Isoniazid resistant tuberculosis in a school outbreak: the protective effect of BCG. Eur Respir J 1991; 4:778-82. 